\title{
The Estimation of Nominal and Real Yield Curves from Government Bonds in Israel
}

\author{
Zvi Wiener \\ mswiener@mscc.huji.ac.il \\ School of Business Administration \\ The Hebrew University of Jerusalem \\ Jerusalem 91905, Israel \\ Helena Pompushko \\ helenap@boi.gov.il \\ Monetary Department \\ Bank of Israel \\ Jerusalem, Israel
}

Acknowledgements. The project was carried out in the Monetary Department of the Bank of Israel. The authors wish to thank members of the Monetary Department of the Bank of Israel for the data and useful comments.

Zvi Wiener acknowledges partial funding of his research from the Krueger Center for Finance and Banking of the School of Business Administration, The Hebrew University, Jerusalem and the Monetary Department of the Bank of Israel. 


\title{
The estimation of nominal and real yield curves from
}

\section{government bonds in Israel}

\begin{abstract}
We develop and test a mathematical method of deriving zero yield curve from market prices of government bonds. The method is based on a forward curve approximated by a linear (or piecewise constant) spline and should be applicable even for markets with low liquidity. The best fitting curve is derived by minimizing the penalty function. The penalty is defined as a sum of squared price discrepancies (theoretical curve based price minus market closing price) weighted by trade volume and an additional penalty for non-smoothness of the yield curve. We apply this method to both nominal and CPI linked bonds traded in Israel (some segments of these markets have low liquidity). The resulting two yield curves are used for derivation of market expected inflation rate. The main problems are low liquidity of some bonds and imperfect linkage to inflation in the CPI linked market. Usage of forward curves as the state space for the minimization problem leads to a stable solution that fits the data very well and can be used for calculating forward rates.
\end{abstract}

\section{Introduction}

The term structure of default free rates is a key element in economic and financial analysis that involves analyzing comparisons of payment streams over time. This term structure data is typically derived from traded government bonds. The term structure appropriate for discounting is based on the zero coupon equivalent yield. If the term structure is to be used in order to derive market expectations for specific time periods in the future, it should also allow for the smooth derivation of the corresponding forward yields. The task of deriving such a curve is much more complex in a relatively illiquid market with noisy data. This task is even further complicated when deriving the term structure of yields on $\mathrm{CPI}^{1}$-indexed bonds, due to the presence of indexation lags, as the CPI is announced once a month, on the $15^{\text {th }}$ of the following month. This time delay means that indexation is only partial for the most recent calendar period. The

\footnotetext{
${ }^{1}$ Consumer Price Index - the average level of consumer prices during the previous month which is reported on a monthly basis by the Central Bureau of Statistics.
} 
combination of nominal and real forward rates contains information on market expectations of inflation. These rates reflect the basic discount factors used for pricing all fixed income securities. There are several principal methods used for deriving the zero coupon yield curve. Many European central banks use the Nelson and Siegel (1987) method or its modification by Svensson (1994). However, the US, Japan and the United Kingdom use the "smoothing splines" method (see BIS paper no 25, Zero-coupon yield curves: technical documentation, October 2005). Many private companies supplying financial data also use variations of the spline method.

In this paper, we develop and test a robust algorithm that derives smooth zero yield curves from bond market data in Israel. The Israeli bond market is based on two main types of linkage nominal bonds and CPI linked bonds. While the nominal bonds are relatively liquid, many segments of the CPI linked bond market suffer from low and time varying liquidity. The CPI linked yield curve is very important since in Israel significant parts of the economic activity (including many legal agreements) are linked to the CPI. The Bank of Israel uses the CPI curve for the derivation of market expected inflation. The zero-coupon yield curves are important input for all of the above. The method described below calculates these curves in a smooth and robust manner.

By smooth we mean that one can derive forward rates from the same curve and get reasonable results, even if the market is not very liquid (infrequent trades, low volume and slow adjustment of prices). By robust we mean an algorithm that does not suddenly change shape from one day to another due to technical reasons. We also expect the shape of the yield curve to be stable, relative to the input data set. For example, when dropping one bond with a small volume of trade we should not expect a significant change in the whole term structure.

The advantage of using the zero-coupon yield curve is that it allows an immediate discount of every single future payment. The alternative that is often used is based on yield to maturity. This yield can be calculated much more easily, but its use is very limited, as it is appropriate only for a given schedule of payments and can not be used for any other cashflow, (which differs either in the coupon amounts or in timing). Thus, the yield to maturity of a coupon bond is not a good measure of the time value of money and it should be stripped before it is used for discounting. The derivation of forward rates is a mathematical procedure that requires taking the derivative of the term structure with respect to the time to maturity. Thus any non-smooth yield curve will lead to artificial jumps in the forward rates and consequently to incorrect conclusions regarding market expectations. 
The liquidity of the Israeli government bond market is low in some segments (short term CPI linked bonds for example). Thus the market data is often noisy and can not be used without taking this into account.

We describe below an algorithm that overcomes these difficulties as it searches for the best fitted yield curve based on forward splines, where the fitting penalty takes into account the liquidity of each issue. Moreover, for the CPI linked bonds we break up the holding period into CPI linked and unlinked periods and discount each cashflow appropriately.

\section{Government bonds in Israel}

The Israeli government bond market has (at the end of 2005) a market capitalization of 262B NIS² with an average daily trade volume in 2005 of about 1.1B NIS. In comparison, the stock market in Israel has a market value of about 506B NIS with an average daily trade volume of 965M NIS, the corporate bond market has a value of 105B NIS with an average daily trade volume of about 250M NIS. Most institutional investors rely on the government bonds as the core of their portfolios.

There are 4 main types of government bonds issued in the local market. They are named Makam, Shahar, Gilon, and Galil. The table below summarizes their main characteristics. The shekel dollar exchange rate in 2005 was around the level of 4.5 NIS $=1$ USD.

\begin{tabular}{|l|l|l|l|l|l|}
\hline Name & $\begin{array}{l}\text { Original } \\
\text { maturity }\end{array}$ & Linkage & Coupon & $\begin{array}{l}\text { Outstanding } \\
\text { notional }\end{array}$ & $\begin{array}{l}\text { Average daily } \\
\text { trade volume }\end{array}$ \\
\hline Makam & Up to 1 year & nominal & Zero coupon & NIS 71 B & NIS 585 M \\
\hline Shahar & 2-15 years & nominal & Fixed, annual & NIS 89 B & NIS 559 M \\
\hline Gilon & 2-10 years & nominal & Floating, annual & NIS 57 B & NIS 163 M \\
\hline Galil & 7-20 years & CPI-linked & Fixed, annual & NIS 114 B & NIS 351 M \\
\hline
\end{tabular}

\section{Methods of calculating zero-coupon yield curves}

There are three types of methods used for the estimation of a zero-coupon yield curve from bond market data. The first one is based on an assumption of a parametric form of a yield curve. The

\footnotetext{
${ }^{2}$ NIS stands for New Israeli Shekel which is the name of the Israeli currency, also referred to as the shekel.
} 
most popular version of this method was developed by Nelson and Siegel (1987). This method assumes that the instantaneous forward rates take the following functional form:

$$
f^{N S}(t)=\beta_{0}+\left(\beta_{1}+\beta_{2} \frac{t}{\tau}\right) \cdot e^{-\frac{t}{\tau}}
$$

Here $\beta_{0}, \beta_{1}$, and $\tau$ are parameters that determine the shape of the term structure. Although this functional form allows for several different shapes of the term structure, Svensson (1994) suggested a richer family with an additional term (and two more parameters).

$$
f^{S v}(t)=\beta_{0}+\left(\beta_{1}+\beta_{2} \frac{t}{\tau_{1}}\right) \cdot e^{-\frac{t}{\tau_{1}}}+\beta_{3} \frac{t}{\tau_{2}} \cdot e^{-\frac{t}{\tau_{2}}}
$$

This form allows for two humps and it includes the Nelson Siegel model as a special case (when $\beta_{3}=0$ ). The problem with the parametric methods like these is that the functional form assumed from mathematical convenience does not reflect the economic behavior of interest rates. Another problem is that a small change in a price of a long term bond can lead to a change of the short end of the derived zero-coupon yield curve for purely technical reasons. The third problem is that often the shape of the yield curve based on a parametric model is not robust and changes significantly after a relatively small change in prices.

The second method is based on bootstrapping and can be used for a very efficient market only, where prices are observed simultaneously; there is a variety of liquid bonds with different maturities covering the whole range of time. This method is not appropriate for a smaller market with few bonds, suffering from low liquidity.

The third method is based on splines (functions defined piecewise). This method was developed in Vasicek and Fong (1982), and Fisher, Nychka, and Zervos (1995). It is based either on a fixed or variable grid and an optimization procedure that minimizes some penalty functions.

The goal of this paper is to construct a robust algorithm for calculating the term structure of interest rates from market prices of traded government bonds. The term structure we are looking for is a zero-coupon term structure that can be directly used for discount factor. Moreover, we would like to have as a result a smooth term structure. The trade off between better matching market prices, robustness and smoothness will be described below. The algorithm is implemented for both nominal and CPI linked sectors.

We use a fixed time grid, and interpolate forward rates between grid nodes using a simple linear function. ${ }^{3}$ Then, for any given set of key forward rates one can calculate the theoretical

\footnotetext{
${ }^{3}$ The same method will work for other types of interpolation between nodes.
} 
prices and the degree of non-smoothness of the resulting curve. The minimization of these two penalties (with some weights) leads to the zero-coupon term structure of interest rates.

\section{Data}

The input of the model is based on the (almost) fixed data base of future cashflows that are reflected in the market price, the daily closing prices of government bonds, the volume of trade, and the anticipated inflation for the period between the last CPI report and the input date.

Due to low liquidity occasionally there are very noisy observations. We apply a filter that excludes any suspicious data, such as bonds that have negative yields, low trade volume, or very unusual price changes.

In order to identify unusual price changes, we analyze the history of each bond over 45-60 days, and calculate the canonical correlations of the past with the current change. This method uses the STATESPACE procedure of SAS and represents a stationary multivariate time series X(t) of dimensions $\mathrm{R}$ in the following form:

$$
Z(t)=F \cdot Z(t-1)+G \cdot E(t) \text { (AIC - Akaike's information criterion) }
$$

Where $\mathrm{Z}(\mathrm{t})$ is the vector process of dimension $\mathrm{S}=\mathrm{R}+1$. The first $\mathrm{R}$ components of $\mathrm{Z}(\mathrm{t})$ are in fact $\mathrm{X}(\mathrm{t})$ and the last component is the prediction of $\mathrm{X}(\mathrm{t}+1)$ based on the history. $\mathrm{F}$ is an S-by-S transition matrix, and G is an S-by-R matrix calculated by SAS. $E(t)$ is an R-dimensional noise independent of $\mathrm{X}(\mathrm{t})$.

The procedure fits a sequence of vector autoregressive models using Yule-Walker equations and selects the order for which Akaike's Information Criterion (AIC) is minimized (0.0001). After using this procedure, we have a residual for each price of each bond. We calculate the average residual for this date over all bonds and compute the ratio of the actual residual of a bond to the average of all bonds on the same date. If the ratio is greater than 3 , we ignore this observation.

Typically the daily set consists of 10-12 bills (Makam), 6-8 notes (Shahar), and 8-34 CPIlinked securities (Galil). The nominal bonds are almost always liquid, while CPI-linked bonds are less liquid, especially those with a time to maturity of up to two years. The CPI -linked bonds also have big price fluctuations (probably also due to illiquidity). 


\section{Description of the algorithm for the nominal yield curve}

For the nominal yield curve we use the following time grid:

$\left(\mathrm{T}_{1}, \mathrm{~T}_{2}, \ldots, \mathrm{T}_{\mathrm{N}}\right)=(0,3 \mathrm{M}, 6 \mathrm{M}, 9 \mathrm{M}, 1 \mathrm{Y}, 2 \mathrm{Y}, 3 \mathrm{Y}, 5 \mathrm{Y}, 7 \mathrm{Y}, 10 \mathrm{Y})$. Define the yet unknown vector of forward rates by $\left(F_{1}, F_{2}, \ldots, F_{N}\right)$. Interpolate the forward rate linearly between the grid nodes by using linear interpolation. For $T_{i}<t<T_{i+1}$ we have

$$
f(t)=\frac{T_{i+1}-t}{T_{i+1}-T_{i}} F_{i}+\frac{t-T_{i}}{T_{i+1}-T_{i}} F_{i+1}
$$

An example of a graph showing piecewise linear interpolation between the nodes of the fixed grid is provided below, in figure 1 . This graph is based on the following forward rates:

$F=(3.58 \%, 3.84 \%, 4.09 \%, 4.32 \%, 4.54 \%, 5.53 \%, 6.67 \%, 8.82 \%, 8.91 \%, 6.82 \%)$.

The forward rates are shown as represented by the dots connected by the thin line and the spot curve is represented by the smoother, thicker line. The graph demonstrates the way that the spot curve is smooth, even when the curve of the forward rates is not.

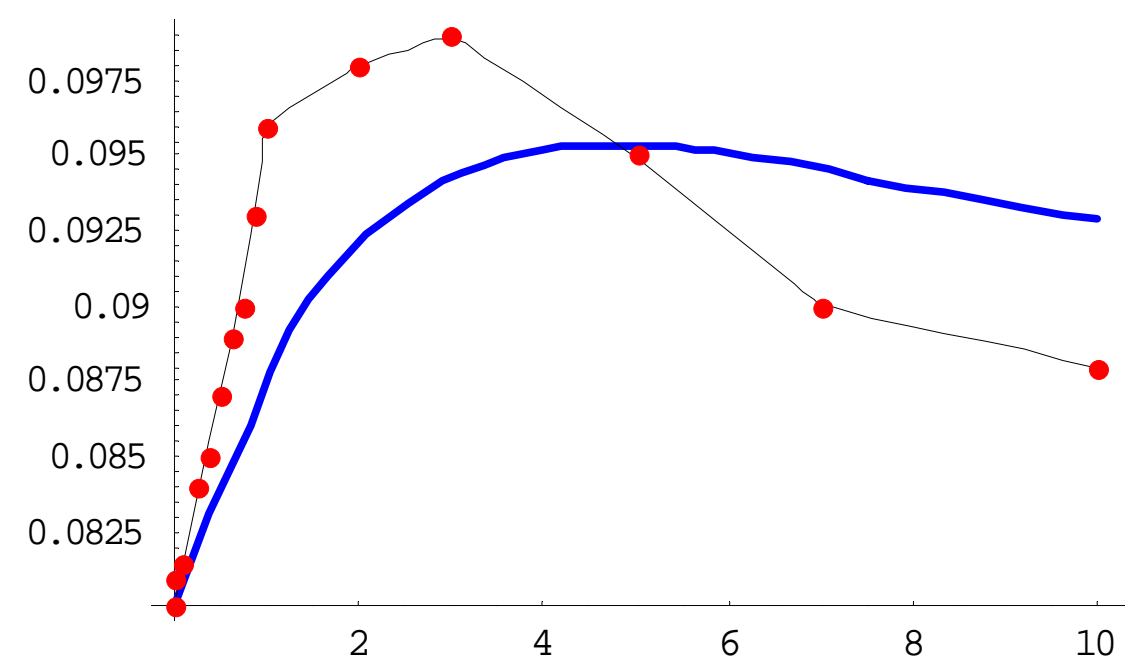

Figure 1. Example of forward (thin) and spot (thick) zero-coupon curves as a function of maturity.

For this forward curve one can calculate the whole yield curve of zero-coupon interest rates by using the following formula (here $f(\tau)$ are interpolated forward rates) as explained in Appendix B: 


$$
r(s)=\frac{1}{s} \int_{0}^{s} f(\tau) d \tau
$$

Then, using this yield curve, one can find a theoretical price for every bond and compare the resulting prices with the actual prices on the Tel Aviv stock exchange. For each bond there will be some difference between the actual and predicted price. We use the sum of squares of all of these differences with weights as a first penalty function $P(F)$.

We use the relative volume of trade as weights for the procedure. This automatically gives a higher weight to a difference between the actual and expected price for a bond with high liquidity. In fact we do not have to calculate the spot curve from the forward rates and then price all of the bonds theoretically. We price each bond from the forward curve directly using the following formula for a present value of one SHEKEL paid at time s:

$$
B(s)=\exp \left(-\int_{0}^{s} f(\tau) d \tau\right)
$$

By working with fixed coupons, we can immediately price each traded bond by summing up its discounted cash flow. The total penalty of the first type is defined as:

$$
P(F)=\sum_{\text {bonds }} \frac{\text { trade }_{\text {tral trade volume }}}{\text { velume }}\left(\text { price }_{i}(F)-\text { market }_{\text {price }}\right)^{2}
$$

The second type of penalty is a penalty for a non-smoothness of the forward curve. It is defined as

$$
Q(F)=\sum_{i=2}^{N-1}\left(\frac{F_{i+1}-F_{i}}{T_{i+1}-T_{i}}-\frac{F_{i}-F_{i-1}}{T_{i}-T_{i-1}}\right)^{2}
$$

The formula above calculates the difference in slopes of the forward curve at each pair of consecutive segments as shown in the figure below.

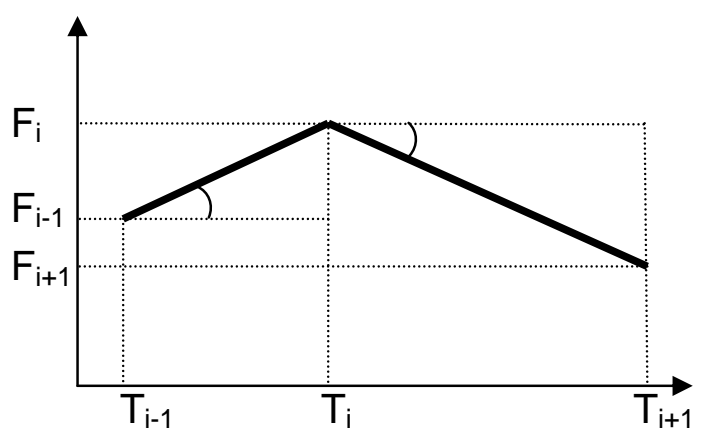

Figure 2. The non-smoothness penalty $\mathrm{Q}(\mathrm{F})$ 
In other words, this penalty measures something similar to the second derivative or degree of nonsmoothness in the forward curve. One can introduce weights for different time intervals. For example, one can demand more smoothness in the short segment or in the long segment of the term structure. In the current algorithm all weights are the same, but in fact the grid nodes are denser in the short part of the term structure, where the lack of smoothness typically takes place.

For each hypothetical tem structure (vector F) we have two types of penalties. The total penalty is defined as

$$
P(F)+w \cdot Q(F)
$$

Notice that the parameter $w$ reflects the relative importance of smoothness versus price matching. A higher $w$ corresponds to a higher importance of smoothness and a lower $w$ corresponds to a higher importance of better price matching. Based on a set of experiments we have chosen the value of $\mathrm{w}$ to be equal 1, as this leads to a good balance of price matching and smoothness.

Now we perform a multidimensional optimization procedure in which we search for an "optimal" term structure that matches the two criteria simultaneously by minimizing the expression (6) over all admissible forward yield curves. A result of this minimization is a forward rate vector $F$. As soon as the optimal forward curve is found, one can calculate the spot curve, using (2). This gives the resulting nominal zero-coupon yield curve.

We observed several cases in which the optimization procedure is not well defined due to a high ratio of the biggest and the smallest eigenvalue of the matrix of second derivatives. In such a case we recommend using the conjugate gradient instead of the method of steepest descent (the gradient method).

\section{CPI linked bonds}

The CPI linked government bonds provide only an approximate indexation due to the fact that the CPI index is measured discretely with a time delay. In fact the "known index" is used each time that a payment occurs. This index is the one that was measured on most recent 15-th day of a month and it reflects the average price level during the month that ended 15 days earlier. For example, if a payment takes place on May 31, the index that was announced on May 15 will be used. This index corresponds to the average price level during the month of April. This creates a delay of approximately a month and a half. 
A similar situation exists when we need to price a linked bond on, say May 10. Then the last reported index was announced on April 15 and it corresponds to the average price level of March. This can create a delay of up to two months.

In general, at any date one can divide the indexation to three areas $a, b, c$ as described in Figure 3 below. Here $t$ is today, $c$ is the payment date, $b$ is the last CPI-linkage (i.e. payment at $c$ will be linked to price changes up to $b$ ). Currently (at time t) the CPI index is officially known up to time $a$. The change of CPI between $a$ and $b$ will affect the payment but is not released yet and should be estimated, the CPI change between $b$ and $c$ will not affect the payment at $c$ (but may affect later payments of the same security).

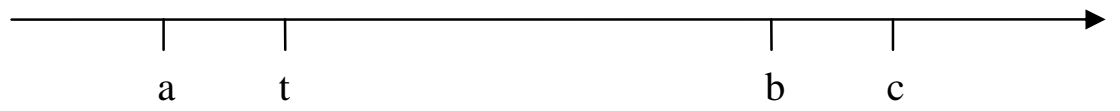

Figure 3. CPI indexation

One can calculate the present value of a single CPI indexed payment in two equivalent ways. First, as an expected nominal payment which is discounted at the nominal interest rate. In this case we have:

$$
P V=A \cdot E\left\{\frac{C P I(t)}{C P I(a)} \frac{C P I(b)}{C P I(t)}\right\} e^{-(b+c) \cdot r(b+c)},
$$

where $A$ is the accumulated CPI index till time $a$. Here $r(b+c)$ is the zero nominal yield to time $(b+c)$ calculated by the algorithm described above. The equation (7) can be used to derive the expected price level at time $b$ from the bond prices directly.

On the other hand, by discounting the CPI-linked payment at real interest rates, the payment can be valued in the following form:

$$
\begin{aligned}
P V & =A \cdot E\left\{\frac{C P I(t)}{C P I(a)}\right\} e^{-b \cdot R(b)} e^{-c \cdot f(b, b+c)}= \\
& =\frac{C P I(a)}{C P I(0)} \cdot \frac{C P I(a+1 M)}{C P I(a)}\left(\frac{C P I(a+2 M)}{C P I(a+1 M)}\right)^{\frac{N d a y s}{31}} e^{-b \cdot R(b)} e^{-\int_{b}^{c} f(s) d s}
\end{aligned}
$$

here $R(b)$ is the current zero-coupon real interest rate at time $b$ and $f(b, b+c)$ is the current nominal forward interest rate for the period starting at $b$ and ending at the time of actual payment $b+c$. 
Assuming that we have a reliable estimate of $C P I(t$,$) one can use equation (8) in order to derive$ the real interest rates from the prices of traded linked bonds.

Similarly to the unlinked bonds, we will use forward rates as a basis for a search for a real zero-coupon yield curve that reflects the observed prices and remains smooth enough. Notice that sometimes the payment is so close that $b$ occurs before $t$, like in the figure below.

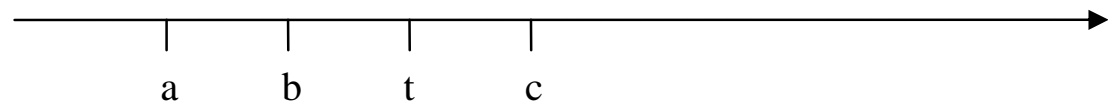

Figure 4. Another possibility of a partial indexation schedule

In this case we should change the pricing formula (8) to

$$
P V=A \cdot E\left\{\frac{C P I(b)}{C P I(a)}\right\} e^{-(c-t) \cdot r(c)}=A \cdot E\left\{\frac{C P I(b)}{C P I(a)}\right\} \cdot e^{-\int_{t}^{c} f(s) d s}
$$

Notice that this can occur for a single payment of a bond. Here $r$ is the nominal interest rate and $C P I(b)$ is the estimated CPI index at date $b$. This means that at each date on which we wish to derive the yield curve, we use the estimated CPI index CPI $(t)$ and the estimated CPI index for the last linkage date $C P I(b)$ (typically the 15-th of last month). For example on August 3, 2005 we need to use an estimate of CPI(03-Aug-05) and estimate of CPI(15-Jul-05). This means that we have to use the two estimates of the CPI by economists as input, one for the month after $a$ and another for the month thereafter.

\section{CPI linked yield curve, algorithm}

The same time grid that we used for calculating the nominal rate is used for calculating the CPI linked yield curve, however, we included only the points on the grid which are one year or longer: $(0,1 \mathrm{Y}, 2 \mathrm{Y}, 3 \mathrm{Y}, 5 \mathrm{Y}, 7 \mathrm{Y}, 10 \mathrm{Y}, 15 \mathrm{Y}, 20 \mathrm{Y})$. The reason for this is that there are very few CPI linked bonds with a time to maturity of less than one year. 
Assume that we have already found the nominal yield curve (including forward rates) as described above. We will choose the same grid for the CPI linked yield curve. ${ }^{4}$ Again, define the two penalty functions $P_{C P I}$ and $Q_{C P I}$ so that $P_{C P I}$ measures the cumulative price discrepancy and $Q_{C P I}$ measures the total degree of non-smoothness.

As in (6), the total penalty is defined as

$$
P_{C P I}\left(F_{C P I}\right)+w_{C P I} \cdot Q_{C P I}\left(F_{C P I}\right)
$$

A similar multi-dimensional minimization procedure ${ }^{5}$ is used to derive the real forward rates. The resulting real zero coupon yield curve is constructed based on forward rates (again linearly interpolated between grid nodes).

After a series of tests we conclude that a good balance of smoothness and price matching can be reached with $\mathrm{w}_{\mathrm{CPI}}=1$.

\section{Examples of the yield curves}

We provide below a few examples of the algorithm for the market data on selected dates. The figure below shows the yields to maturity of the Galil (big dots), the forward rates (thin piecewise linear line), and the resulting real zero coupon yield curve (thick line). All this is based on data from 30-Dec-04 (Figure 5) and 26-Jan-06 (Figure 6) using the weight of $w_{C P I}=1$.

\footnotetext{
${ }^{4}$ Note that in reality there are very long CPI linked bonds (till 2024) and we do not have such a long nominal yield curve. We ignored all real bonds with more than $T_{N}=10$ years to maturity, unless longer nominal bonds are available. ${ }^{5}$ Part of the problem here is that we minimize a function with a not well-defined matrix of second derivatives. This takes place when some types of change lead to a very fast change of penalty, while others lead to a much slower change. There are mathematical methods, like conjugate gradient method that make the convergence significantly faster.
} 


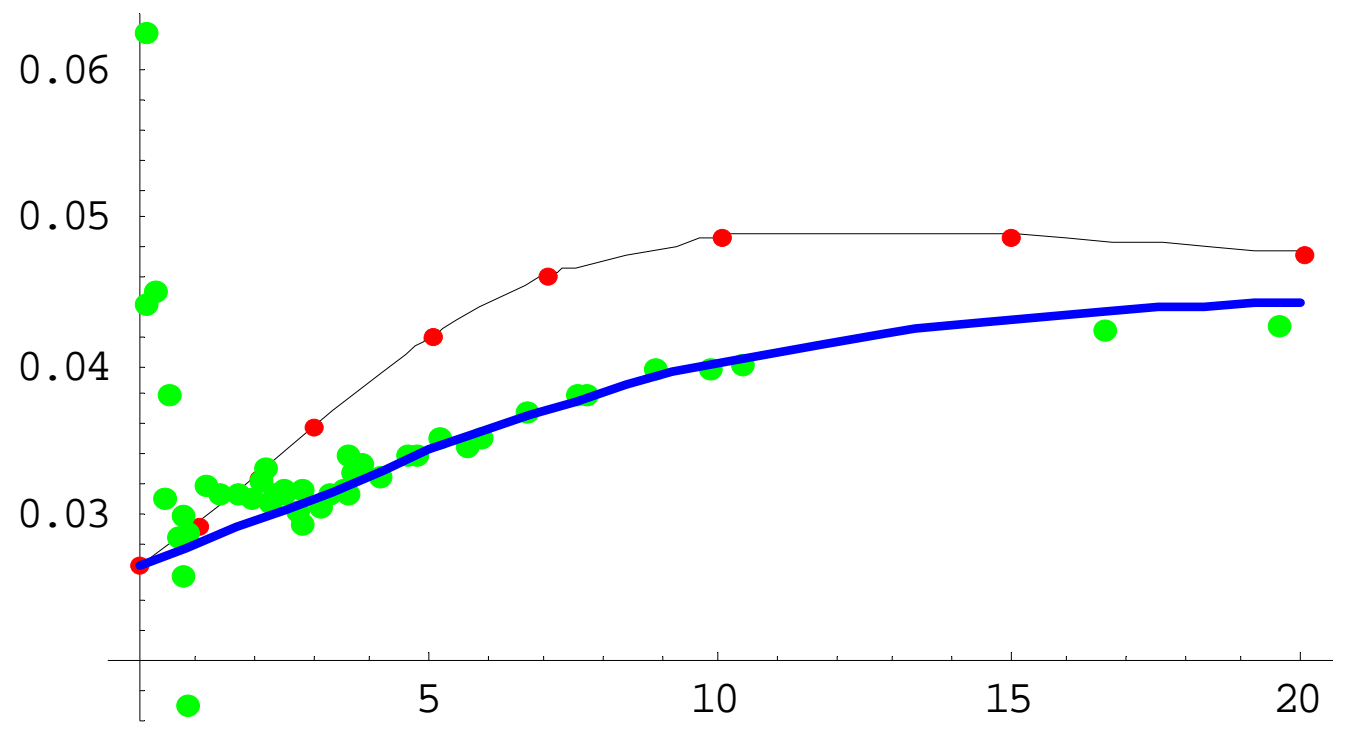

Figure 5. Forward (thin) and spot (thick) curves on 30-Dec-04 versus the naïve yield on government CPI linked bonds.

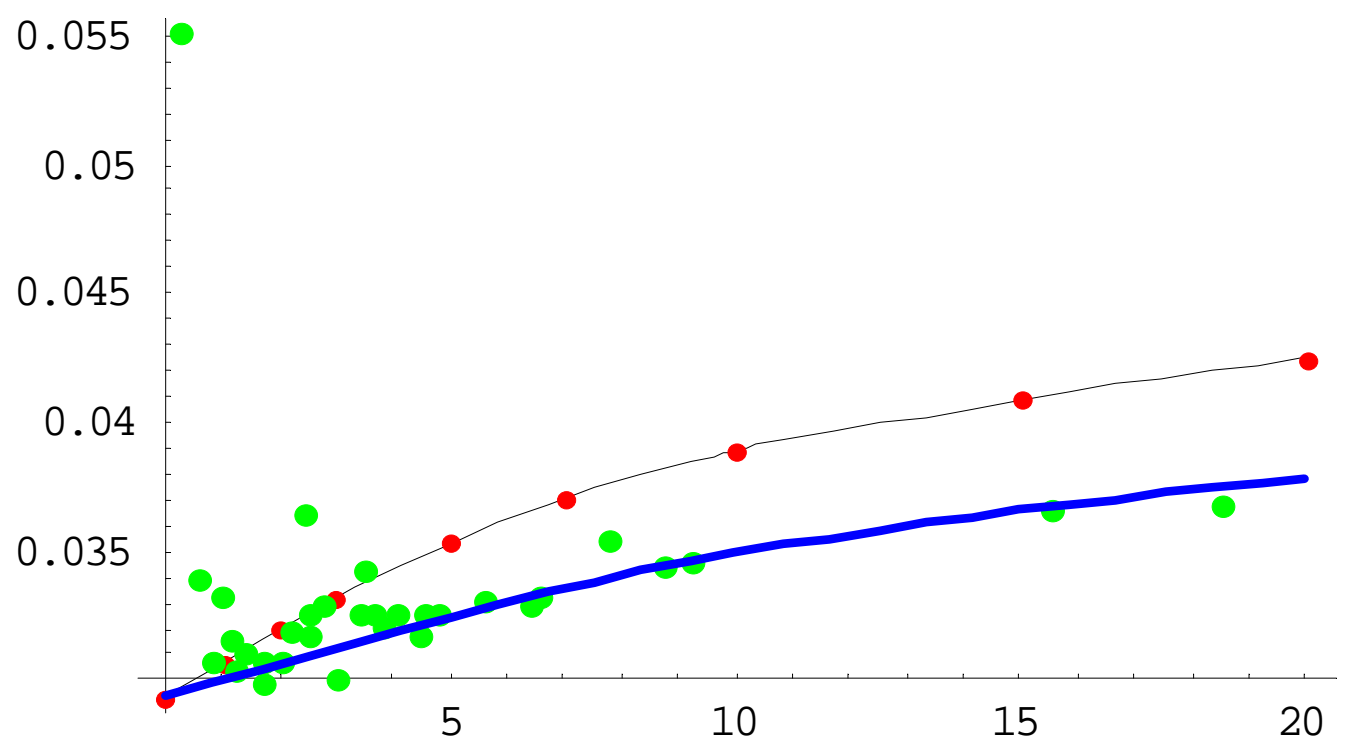

Figure 6. Forward (thin) and spot (thick) curves on 26-Jan-06 versus the naïve yield on government CPI linked bonds. 


\section{Conclusions}

We described the algorithm for the calculation of nominal and real zero coupon yield curves based on the market prices of actively traded government bonds. The algorithm was checked on a set of test dates. The results are stable in the nominal sector (where most securities have large volumes of trade) and less stable in the CPI linked sector (where there are many similar securities, but the volume of trade is significantly lower). We did not treat the problem of differential taxation.

The methods described above were used for the time interval between 2002 and 2005. The results are summarized in the table below.

Table I. Nominal market

\begin{tabular}{|l|r|r|r|r|r|}
\hline Year & $\begin{array}{l}\text { Average } \\
\text { penalty P(F) }\end{array}$ & \multicolumn{1}{l|}{$\begin{array}{l}\text { Average } \\
\text { penalty Q(F) }\end{array}$} & $\begin{array}{l}\text { Average maximal } \\
\text { price discrepancy }\end{array}$ & $\begin{array}{l}\text { Maximal } \\
\text { penalty P(F) }\end{array}$ & \multicolumn{1}{l|}{$\begin{array}{l}\text { Maximal } \\
\text { penalty Q(F) }\end{array}$} \\
\hline 1995 & 0.00019912 & 0.00004231 & 0.00271058 & 0.00202867 & 0.00191745 \\
\hline 1996 & 0.00061616 & 0.00038577 & 0.00301742 & 0.00376206 & 0.04295497 \\
\hline 1997 & 0.00036961 & 0.00012041 & 0.00268151 & 0.00129135 & 0.0040675 \\
\hline 1998 & 0.00044543 & 0.00037451 & 0.00392317 & 0.00286292 & 0.03180163 \\
\hline 1999 & 0.00030895 & 0.00020416 & 0.00317214 & 0.00422597 & 0.01969284 \\
\hline 2000 & 0.00015075 & 0.00005678 & 0.00220443 & 0.00105488 & 0.00050604 \\
\hline 2001 & 0.00009783 & 0.00063031 & 0.00168517 & 0.00049505 & 0.01041794 \\
\hline 2002 & 0.00052569 & 0.0008972 & 0.00312008 & 0.0019481 & 0.01376081 \\
\hline 2003 & 0.00029558 & 0.00020568 & 0.00225065 & 0.00132057 & 0.00424967 \\
\hline 2004 & 0.00006877 & 0.00012146 & 0.00128336 & 0.00026141 & 0.00039588 \\
\hline 2005 & 0.00006066 & 0.00011118 & 0.00104553 & 0.0003632 & 0.00079519 \\
\hline
\end{tabular}

Table II. CPI-linked market

\begin{tabular}{|r|r|r|r|r|r|}
\hline Year & \multicolumn{1}{l|}{$\begin{array}{l}\text { Average } \\
\text { penalty P(F) }\end{array}$} & $\begin{array}{l}\text { Average } \\
\text { penalty Q(F) }\end{array}$ & \multicolumn{1}{l|}{$\begin{array}{l}\text { Average maximal } \\
\text { price discrepancy }\end{array}$} & $\begin{array}{l}\text { Maximal } \\
\text { penalty } \mathrm{P}(\mathrm{F})\end{array}$ & \multicolumn{1}{l|}{$\begin{array}{l}\text { Maximal } \\
\text { penalty Q(F) }\end{array}$} \\
\hline 1995 & 0.00445278 & 0.00138223 & 0.03150984 & 0.00788276 & 0.02491381 \\
\hline 1996 & 0.00469162 & 0.00037321 & 0.03959047 & 0.01228763 & 0.0065063 \\
\hline 1997 & 0.00506843 & 0.00052505 & 0.04449232 & 0.01081413 & 0.01506305 \\
\hline 1998 & 0.00608959 & 0.00028228 & 0.03930329 & 0.01731635 & 0.0028997 \\
\hline 1999 & 0.00565758 & 0.00047301 & 0.03164155 & 0.01222326 & 0.00615298 \\
\hline 2000 & 0.00651909 & 0.0005244 & 0.03548496 & 0.01477713 & 0.01517334 \\
\hline 2001 & 0.00474502 & 0.00000417 & 0.03116842 & 0.01126441 & 0.00019656 \\
\hline 2002 & 0.0065881 & 0.00004717 & 0.03065667 & 0.01998013 & 0.00631004 \\
\hline 2003 & 0.003049 & 0.00000819 & 0.01763947 & 0.01298504 & 0.00051435 \\
\hline 2004 & 0.00253383 & 0.00001512 & 0.01528335 & 0.01352882 & 0.00062942 \\
\hline 2005 & 0.0027984 & 0.00005492 & 0.01271862 & 0.02142882 & 0.00303158 \\
\hline
\end{tabular}

\footnotetext{
${ }^{6}$ We take the maximal price discrepancy in percents each business day and take the average of this number over the year.

${ }^{7}$ Maximal daily penalty over a specific year.

${ }^{8}$ We take the maximal price discrepancy in percents each business day and take the average of this number over the year.

${ }_{9}^{9}$ Maximal daily penalty over a specific year.
} 
We provide in the Figure 7 below the cumulative distribution function of the pricing error based on the nominal bonds between 1995 and 2006 (61,131 data points). The horizontal axis represents the pricing error in basis points (10bp means $0.1 \%$ ), while the vertical axis is the cumulative distribution function of the price discrepancies.

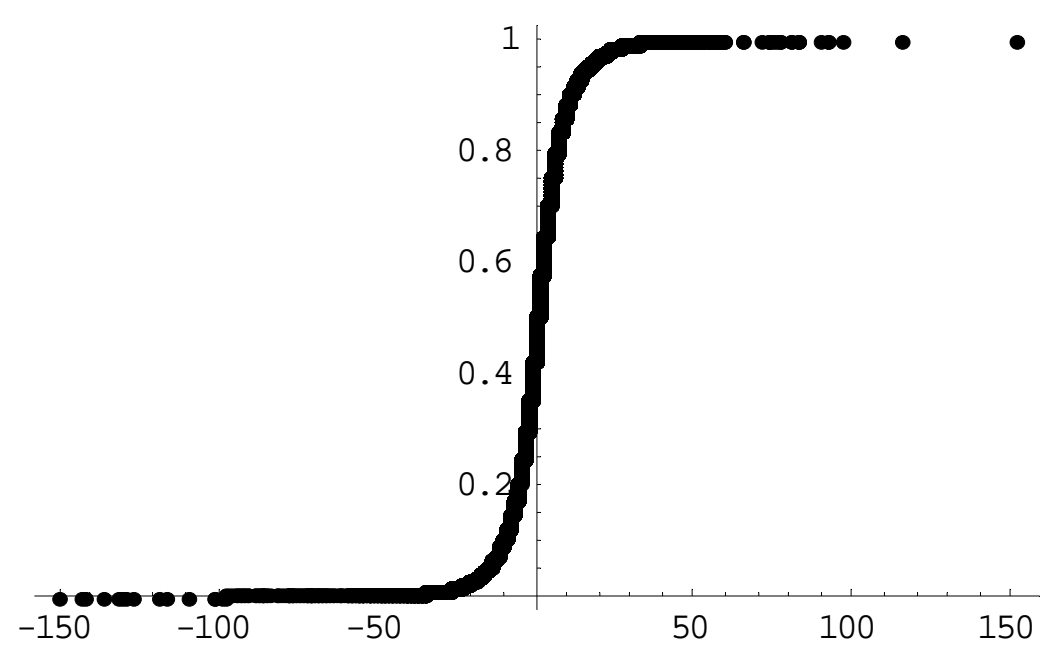

Figure 7. The cumulative distribution function of the pricing error based on nominal bonds during 1995-2006. Price discrepancies (the horizontal axis) are in basis points.

All the price discrepancies are between -150 and +150 basis points. Out of the sample of 61,131 observations $99.9755 \%$ are between $-1 \%$ and $+1 \%$, and $99 \%$ of the price discrepancies are between -36bp and +36bp. For a market with low liquidity (especially during 1995-1998) this is a very good result.

Based on these results, the monetary department of the Bank of Israel switched over to this new method of defining the zero-coupon yield curve for the purpose of inflation forecast. Similar algorithms are used by many companies world-wide, like RiskMetrics (www.riskmetrics.com), Kamakura (www.kamakuraco.com), and Episolutions (www.episolutionsinc.com).

\section{References}

Andersen, L. (2005), Yield Curve Construction with Tension Splines, working paper, http://papers.ssrn.com/sol3/papers.cfm?abstract_id=871088

Anderson, N. and Sleath, J. (1999), “New estimates of the UK real and nominal yield curves”, 
Bank of England Quarterly Bulletin, 384-392.

Anderson, N. and Sleath, J., New Estimates of the UK real and nominal yield curves. http://ideas.uqam.ca/ideas/data/Papers/boeboeewp126.html or http://www.bankofengland.co.uk/qb/qb990403.pdf

Bank of International Settlements, (March 1999), “Zero-Coupon Yield Curves: Technical Documentation”.

Bank of International Settlements, (October 2005), “Zero-Coupon Yield Curves: Technical Documentation”, Monetary and Economic Department.

Brousseau, V. (2002), The functional form of yield curves, Working Paper 148, European Central Bank.

Deacon, M. and Derry, A. (1994), Estimating the Term Structure of Interest Rates, Bank of England.

Deriving and Fitting Interest Rate Curves Using MATLAB ${ }^{\circledR}$ and the Financial Toolbox, Financial Engineering Technical Brief, www.mathworks.com

Evans, M. (1998), Real Rates, Expected Inflation and Inflation Risk Premia, Journal of Finance, 53(1), 187-218.

Fisher, M., Nychka, D. and Zervos, D. (1995), "Fitting the Term Structure of Interest Rates with Smoothing Splines,” Working Paper 95-1, Finance and Economics Discussion Series, Federal Reserve Board.

Fisher, M. and Zervos, D. (1996), Yield Curve, in Computational Economics and Finance, ed. H. Varian, Springer, p. 269-302.

Gerlach, S. (2001), “Interpreting the Term Structure of Interbank Rates in Hong Kong”. Hong Kong Institute for Monetary Research Working Paper, No.14.

Hagan, P. and West, G. (November 2004), "Interpolation methods for yield curve construction”, unpublished manuscript. 
Hull, J. (2000), Options, Futures and Other Derivatives, Prentice Hall, 4-th ed., p. 87-95.

Indian term structure, http://www.indiainfoline.com/bisc/iimappr2.html

Ioannides, M. (2003), A comparison of yield curve estimation techniques using UK data, Journal of Banking and Finance, 27, 1-26

Maltz, A. (2002), Estimation of zero-coupon curves in DataMetrics, RiskMetrics Journal, 3 (1), 27-39.

Monetary Authority of Singapore, (May 1999), “The Term Structure of Interest Rates, Inflationary Expectations and Economic Activity: Some Recent US Evidence”, Occasional Paper No.12.

Nelson, C.R. and Siegel, A.F. (1987), "Parsimonious Modelling of Yield Curves”, Journal of Business, 60, pp. 473-89.

Svensson, L.E.O. (1994), “Estimating and interpreting forward interest rates: Sweden 1992-1994”, NBER Working Paper Series, No.4871.

Svensson, L.E.O. (1995), “Estimating Forward Interest Rates with the Extended Nelson \& Siegel Method”, Quarterly Review, Sveriges Riksbank, Nu. 3, 13-26.

Vasicek, O.A. and Fong, H.G. (1982), “Term Structure Modeling Using Exponential Splines”, Journal of Finance, 37:2, p. 339-348.

Waggoner, D. (November 1997), Spline Methods for Extracting Interest Rate Curves from Coupon Bond Prices, Federal Reserve Bank of Atlanta, Working Paper 97-10, http://mscf.gsia.cmu.edu/BPM/WaggonerSpline.pdf

Wets, R. Bianchi, S. and Yang, L., Serious Zero-Curves, manuscript, available at www.episolutionsinc.com.

Yu, I. and Fung, L. (2002), Estimation of Zero-Coupon yield curves based on exchange fund bills and notes in Hong Kong, Hong Kong Monetary Authority. 
Zangari, P. (1997), An investigation into term structure estimation methods for RiskMetrics, RiskMetrics Monitor, pp. 3-31. 


\section{Appendix A. Discrete and continuous discounting}

According to the Monetary Department of the Bank of Israel, the discrete discounting method used in Israel is based on the following formula:

$$
\text { Price }=\sum_{\text {payments }} \frac{C_{i}}{(1+y)^{\frac{D_{i}}{365}}}=\sum_{\text {coupons }} \frac{(1+c)^{\frac{D_{i}}{365}}-1}{(1+y)^{\frac{D_{i}}{365}}}+\frac{1}{(1+y)^{\frac{D_{T}}{365}}},
$$

where $c$ is the coupon rate, $D_{i}$ is the number of days between the current date and the coupon payment. This is the act/365 method and the actual coupon payments are bigger in leap years.

This means that the continuously compounded zero-coupon yield based on 365 days in a year can be translated to discrete yield according to:

$$
e^{-\frac{D}{365} y_{c}}=\frac{1}{\left(1+y_{d}\right)^{\frac{D}{365}}}
$$

or equivalently

$$
y_{c}=\ln \left(1+y_{d}\right)
$$

and the final formula for translating continuously compounded yield into daily yield is:

$$
y_{d}=e^{y_{c}}-1
$$

\section{Appendix B. Forward rates}

Definitions:

Denote by $t$ - current time (date) and by $B(s)$ price of a zero coupon bond maturing at $s$. Then using continuous discounting we can define the zero-coupon yield curve as $B(s)=e^{-s r(s)}$, or equivalently $r(s)=-\frac{\ln (B(s))}{s}$.

As soon as the whole term structure of interest rates is known, one can derive the implied forward rates by using the following algorithm:

Denote by $\mathrm{r}(\mathrm{t})$ the zero coupon continuously compounded interest rate. Then a forward loan (of size 1) starting at $\mathrm{S}$ and maturing at $\mathrm{T}$ can be valued as follows:

$$
0=1 \cdot e^{-r(S) S}-x \cdot e^{-r(T) T}
$$

thus $X=e^{r(T) T-r(S) S}$, this means that the continuously compounded interest on this loan is $e^{r(T) T-r(S) S}=e^{(T-S)^{*} y}$ and (see also formula 4.1 in Hull) the forward rate between $\mathrm{S}$ and $\mathrm{T}$ : 


$$
y(S, T)=\frac{r(T) T-r(S) S}{T-S}
$$

Note that this formula is very similar to differentiation and the fact that we use a piecewise linear interpolation will lead to artificial jumps near our grid points. For example, if the two years zero coupon rate $r(2)=10 \%$ and a similar 3 years rate is $r(3)=10.75 \%$, the corresponding forward rate is $y(2,3)=12.25 \%$.

An instantaneous forward rate can be derived when the two dates $\mathrm{S}$ and $\mathrm{T}$ are very close. In order to derive the limit rate when T->S we can use the L'Hopitale rule (see Hull p. 95):

$$
\operatorname{Lim}_{T \rightarrow S} \frac{r(T) T-r(S) S}{T-S}=\operatorname{Lim}_{\Delta \rightarrow 0} \frac{r(S+\Delta)(S+\Delta)-r(S) S}{\Delta}=r(S)+S \cdot \frac{\partial r(S)}{\partial S}
$$

The instantaneous forward rate is

$$
f(S)=r(S)+S \cdot \frac{\partial r(S)}{\partial S}
$$

Note that the discounting can be done easily with the forward rates. The present value of 1 paid at time $\mathrm{T}$ is

$$
B(T)=\exp \left(-\int_{0}^{T} f(s) d s\right) .
$$

\section{Appendix C. Example of a difference between naive and correct rates}

Due to the special features of CPI linked bonds there can be a significant difference between naive and properly calculated interest rates. To demonstrate such an example, see the following Figure 8, where the points represent the naively calculated yields on Galil and the thick line shows the calculated CPI linked zero coupon curve as of 18-May-2003. It seems that the calculated yield curve is too low (at least for long time horizon). However when looking at the price match one can see that the differences between actual and predicted prices are distributed around zero. To explain this phenomenon let us consider the following example. 


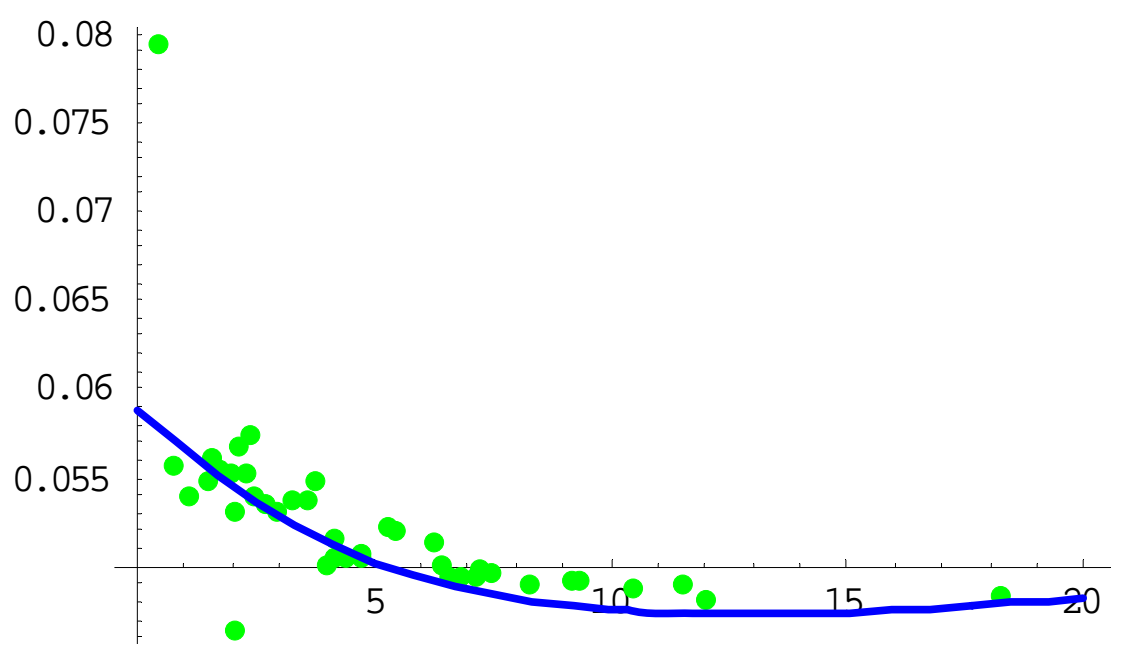

Figure 8. Example of misleading appearance.

Consider a CPI linked bond issued today without coupons. It will pay 100 CPI linked shekels at time T. However the linkage to CPI is until time b only. Typically T-b is about 1-1.5 months. Then the correct formula for continuously compounded yield is

$$
p=100 \cdot e^{-R \cdot b} e^{-f \cdot(T-b)}
$$

Here $\mathrm{p}$ is the current price of the bond, $\mathrm{R}$ is the continuously compounded CPI linked zero coupon yield for maturity $b, f$ is the nominal forward rate starting at $t$ and ending at $T$. The formula for $R$ through price becomes:

$$
R=\frac{1}{b}\left(\log \left(\frac{100}{p}\right)-f(T-b)\right)
$$

The naive formula for yield would be

$$
p=100 \cdot e^{-r \cdot T}
$$

And the corresponding naive yield is

$$
r=\frac{1}{T} \log \left(\frac{100}{p}\right)
$$

Let's use some numbers to see the difference. Assume that $\mathrm{b}=1$ year, $\mathrm{T}=1$ year and 1 month, and the forward nominal rate $\mathrm{f}=10 \%$, and price $\mathrm{p}=93$. Then we get

$$
\begin{aligned}
& R=6.4 \%, \\
& r=6.7 \%,
\end{aligned}
$$

The difference is similar to what we get on Figure 8. 